\title{
Physico-chemical Properties of Denbi Reservoir for Fish Production in Bench Maji Zone, Ethiopia
}

\author{
Askale Gebremichael $^{1^{*} \quad \text { Tegegn Fantahun }}{ }^{2}$ \\ 1.Mizan-Tepi University, Department of Animal sciences, P.O. Box 260, Mizan-Teferi, Ethiopia \\ 2.Agriculture Biotechnology Directorate, Ethiopian Biotechnology Institute, P. O. Box 5954, Addis Ababa, \\ Ethiopia
}

\begin{abstract}
Water quality is made up of physical, chemical and biological factors which influence the use of water for fish culture purposes. The objective of this study was to analyze physicochemical properties of water in Denbi reservoir. Field and laboratory work were conducted to generate the data. The collected data were analyzed by using descriptive statistics and one-way ANOVA test. The result of the study showed that the mean and standard deviation of physicochemical parameter of water obtained were as follows: Temperature $\left(25.14 \pm 1.12^{\circ} \mathrm{C}\right), \mathrm{pH}$ $(8.25 \pm 0.31)$, Conductivity $(48.94 \pm 1.55 \mu \mathrm{S} / \mathrm{cm})$, TDS $(24.16 \pm 0.49 \mathrm{mg} / \mathrm{L})$, Turbidity (24.54 $\pm 3.02 \mathrm{NTU})$, transparency $(33.90 \pm 5.18 \mathrm{~cm})$, Total hardness $(0.27 \pm 0.03 \mathrm{mg} / \mathrm{L})$, Calcium hardness $(1.57 \pm 0.30 \mathrm{mg} / \mathrm{L})$, Iron $(0.005 \pm 0.003 \mathrm{mg} / \mathrm{L})$, Manganese $(0 \mathrm{mg} / \mathrm{L})$, Nitrates $(0.07 \pm 0.03 \mathrm{mg} / \mathrm{litter})$ and Sulphate $(0.15 \pm 0.01 \mathrm{mg} / \mathrm{L})$, respectively. The Physic-chemical properties of water in Denbi reservoir indicated that it is fit for fish production except total hardness and calcium hardness which were below the standards.
\end{abstract}

Keywords: Denbi reservoirs, fish production, physico-chemical properties, water quality

DOI: $10.7176 / \mathrm{CMR} / 11-5-01$

Publication date:May $31^{\text {st }} 2019$

\section{INTRODUCTION}

\section{1 back ground of the study}

Fish is one of the known aquatic animals used for human consumption as food[1,2]. Fish represent a prized source of nutrients of ultimate importance for balanced and healthy diets [3]. Water is the culture milieu for fish and other aquatic organisms. It is the physical care in which they carry out their life functions such as nourishing, swimming, breeding, digestion and excretion[4,5] based on this, access to adequate, regular and endless supply of good quality water is essential in any aquaculture program. Water quality generally means the component of water which must be present for optimum growth of aquatic organisms [6]. Water quality is made up of physical, chemical and biological factors which influence the use of water for fish culture purposes. According to [7] any water body is a potential medium for the production of aquatic organisms. All living organisms have tolerable limits of water quality parameters in which they perform optimally. A sharp drop or an increase within these limits has adverse effects on their body functions [8].

Ethiopia is home to a fisheries sector. The present-day production is still far below the estimated potential yield, which proposes scope for further expansion of the fishery. Water bodies located in the Rift Valley show signs of overexploitation whereas those located in remote areas with poor infrastructure, and which make up the majority of rivers, lakes and reservoirs, remain underutilized [9]. Denbi reservoir is located in Bench- Maji Zone. The reservoir was established to generate electricity. Denbi Mini Hydroelectric power plant operation fully ceased to generate electricity in 2006.

\subsection{Statement of the problem}

According to report of [2] Denbi reservoir is estimated about $72 \mathrm{~km}^{2}$ area, which having fishery potential 383 tonne/year and catch 77 tonne However, there is a lack of information on water physic-chemical properties of Denbi reservoir for fish production suitability.

\subsection{Significance statement}

This study identified the water quality properties of Denbi reservoir in respect to suitability for fish production. The physico-chemical parameters below recommended standard identified should be corrected for increasing the productivity of fish.

\subsection{Objectives}

To analyze selected phsico-chemical parameters of water of the reservoir for fish.

\section{MATERIALS AND METHODS}

\subsection{The Study Area}

The study was conducted in Denbi reservoir which is found in the boundary between Fanika Kebele of South 
Bench and Fajika Kebele of ShekoWereda, Bench Maji Zone. The zone is located at a distance $585 \mathrm{~km}$ south of Addis Ababa. The areas are characterized by elevation of 1451 meter above sea level. The astronomical location of the area has latitude $6^{\circ} 56^{\prime}-7^{\circ} 0^{\prime} \mathrm{N}$ \&longitude $35^{\circ} 30^{\prime}-35^{\circ} 36^{\prime} \mathrm{E}$. The amount of rain fall is abundant with main annul distribution varying from $1801-2000 \&$ the temperature of the area $20.25^{\circ} \mathrm{c}$. The total population found in the study area is 47318 \& the agro- ecology of the people is low land.

\subsection{Method of Data Collection}

\subsubsection{Site selection for water sampling}

Sampling sites for the water body were purposively selected to represent the water quality at different points. Five sampling sites were selected at (one inlet, three centres and one outlet). The sampling sites for water were also fixed first using GPS. A Garmin GPS was used to record the sampling coordinates. The coordinates were later transformed to be able to visualize them in ArcGIS (Fig 1). Water sampling and analysis was carried out in the rain season June 2017.

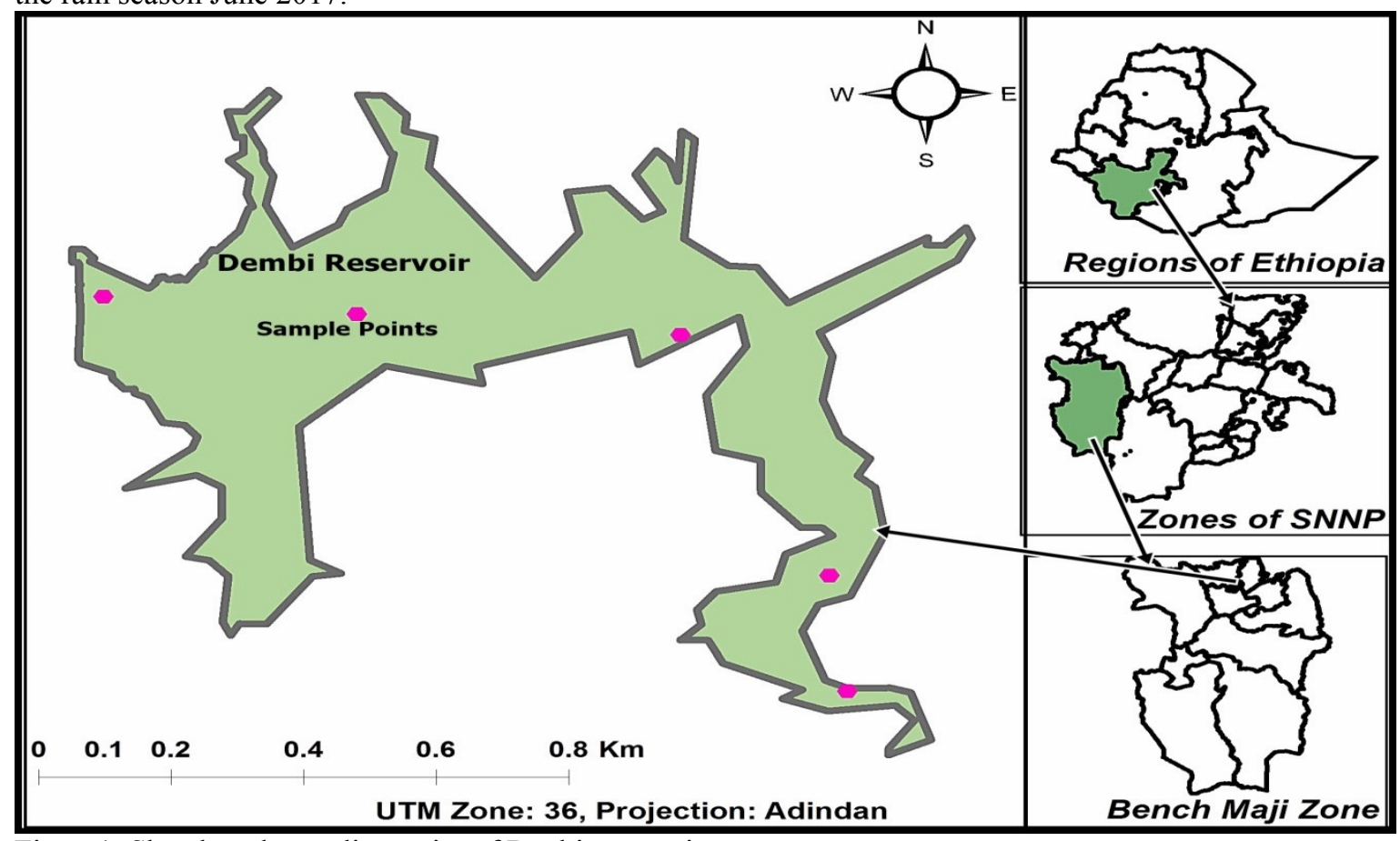

Figure1. Sketch and sampling point of Denbi reservoir

Source: GPS map during this study (2017)

2.2.2. Data collected at the sampling sites: the following parameters such as water temperature $\left({ }^{\circ} \mathrm{C}\right), \mathrm{pH}$, Total Dissolved Solids (TDS) $\left(\mathrm{mg}^{-1}\right)$ and conductivity $\left(\mu \mathrm{sm}^{-1}\right)$ were measured using Palinetest Micro800 Multi, turbidity was measured by Palinetest Turbimeter and water transparency $(\mathrm{cm})$ were measured by using Secchi-disc.

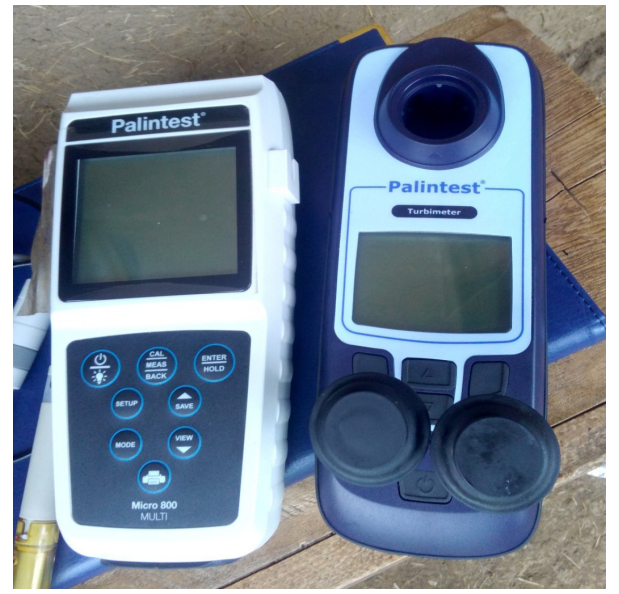

Figure 2. Palinetest Micro800 Multi(left) and PalinetestTurbimeter(right)

2.2.3. Data collected in laboratory: Physico-chemical analysis was carried out after few hours of sampling. Water samples were tested at Mizan-Aman water laboratory center for the following 
physicochemical characteristics including sulphate, nitrate, total hardness, calcium hardness, iron and manganese. To analyze every sample's chemical constituents a photometer (8000model) was used. Each sample was tested for a number of different chemical parameters with more or less the same execution. First a sample was poured into a $10 \mathrm{ml}$ round test tube. Another $10 \mathrm{ml}$ was poured into another test tube and mixed with crushed Palintest tablets. Every parameter had its unique tablets. Each parameter required a certain time to stand in order to get full color development. The time varied from a couple of seconds to 20 minutes. When the solution was fully blended the blank sample was put into the photometer. The wavelength on the photometer was corrected for each and every parameter of interest (between 410-640 nm). When the correct wavelength was set the reading button was pushed until the display showed $100 \%$. The blank sample was removed and replaced with the solution. A new reading was displayed and it was recorded. Each parameters calibration chart was then consulted in order to get the true value of the specific chemical content, in milligram per liter $(\mathrm{mg} / \mathrm{L})$.

\subsection{Data Analysis}

The data collected were stored in a database created in MS Excel. Descriptive statistics such as mean and standard deviation and one-way ANOVA test were employed to see differences among sites using statistical analysis tool, SPSS for window (version 20) at $95 \%$ significance level. In addition, transparency of the water was analyzed using following formula Transparency: Transparency of the water was measured using Secchi disc. The disc was carefully let down into the water bodies, and the depth at which it disappeared from sight was recorded as depth one $\left(d_{1}\right)$. The disc was then raised up gently, and the depth at which it comes into view was noted as depth two $\left(d_{2}\right)$. The average of the two readings $\left(d_{1}\right.$ and $\left.d_{2}\right)$ was taken as the transparency of the reservoir in centimeter $(\mathrm{cm})$.

\section{RESULTS}

The result of physico-chemical properties analysis of water temperature, $\mathrm{pH}$, Depth, TDS, Turbidity, Conductivity, Transparency, Sulphate, Nitrate, Total hardness, Irone and Calcium hardness in the reservoir is presented in Table 1.

Table 1. The physic-chemical properties of water in the Denbi reservoir

\begin{tabular}{lcccccc}
\hline Parameter & Site1 & Site2 & Site3 & Site 4 & Site5 & Mean \pm SD \\
\hline Temperature $\left({ }^{\circ} \mathrm{C}\right)$ & 23.6 & 25.2 & 26.2 & 26.2 & 24.5 & $25.14 \pm 1.12$ \\
pH & 8.74 & 8.20 & 8.31 & 8.08 & 7.92 & $8.25 \pm 0.31$ \\
TDS $(\mathrm{mg} / \mathrm{L})$ & 24.5 & 24.1 & 24.7 & 24.1 & 23.4 & $24.16 \pm 0.49$ \\
Conductivity $(\mu \mathrm{s} / \mathrm{cm})$ & 51.1 & 49.1 & 49.4 & 48.2 & 46.9 & $48.94 \pm 1.55$ \\
Transparency $(\mathrm{cm})$ & 35 & 25 & 35 & 38.5 & 36 & $33.90 \pm 5.18$ \\
Turbidity $(\mathrm{NTU})$ & 23.9 & 22.5 & 22.6 & 23.9 & 29.8 & $24.54 \pm 3.02$ \\
Depth $(\mathrm{m})$ & 6.3 & 3.7 & 4.8 & 4.7 & 1.54 & $4.2 \pm 0.12$ \\
Sulphate $(\mathrm{mg} / \mathrm{L})$ & 0.16 & 0.15 & 0.15 & 0.14 & 0.16 & $0.15 \pm 0.01$ \\
Nitrate $(\mathrm{mg} / \mathrm{L})$ & 0.0704 & 0.0572 & 0.0748 & 0.044 & 0.1056 & $0.07 \pm 0.03$ \\
Total hardness $(\mathrm{mg} / \mathrm{L})$ & 0.29 & 0.23 & 0.29 & 0.31 & 0.24 & $0.27 \pm 0.03$ \\
Iron $(\mathrm{mg} / \mathrm{L})$ & 0.006 & 0.005 & 0.007 & 0.001 & 0.008 & $0.005 \pm 0.003$ \\
Calcium hardness $(\mathrm{mg} / \mathrm{L})$ & 1.78 & 1.8 & 1.06 & 1.64 & 1.58 & $1.57 \pm 0.30$ \\
\hline
\end{tabular}

m: meter, mg/L: milligram per liter, $\mu \mathrm{s} / \mathrm{cm}$ : micro Siemens/centimeter, NTU: Nephelometric Turbidity Unit , TDS: total dissolved solid

\section{DISCUSSION}

The value of water temperature varies from $23.6^{\circ} \mathrm{C}$ to $26.2^{\circ} \mathrm{C}$ in the current study whereas the desirable range of water temperature for fish survival is $20-30^{\circ}[10]$. C. The water temperature obtained in the study was suitable for fish production. $\mathrm{PH}$ value in the study is tending towards alkaline which is within the values for optimum fish survival and productivity. Fish are known to have an average blood $\mathrm{pH}$ of 7.4; therefore fresh water with $\mathrm{pH}$ within this average is optimum and it has been reported that the $\mathrm{pH}$ between 6.5 and 9 is suitable for improved fish production [11].

Conductivity in this study ranged from 46.9 to $51.1 \mu \mathrm{S} / \mathrm{cm}$. Distilled water has a conductivity of about 1 $\mu \mathrm{s} / \mathrm{cm}$ and natural waters have conductivity of 20-1500 $\mu \mathrm{s} / \mathrm{cm}$ [12]. Conductivity of freshwater varies between 50 to $1500 \mu \mathrm{s} / \mathrm{cm}[13]$ but in some polluted waters it may reach $10,000 \mu \mathrm{s} / \mathrm{cm}$ and seawater has conductivity around $35,000 \mu \mathrm{s} / \mathrm{cm}$ and above. As fish differ in their ability to maintain osmotic pressure, therefore the optimum conductivity for fish production differs from one species to another. Stone and Thomforde [14] suggested the desirable range 100-2,000 $\mu \mathrm{s} / \mathrm{cm}$ and acceptable range 30-5,000 $\mu \mathrm{s} / \mathrm{cm}$ for pond fish culture.

TDS values obtained from this work ranged from 23.4 to $24.7 \mathrm{mg} / \mathrm{L}$. The TDS values compare sensibly well 
with results obtained that of Agbaire et al [11]. Dissolved solids are solids that are in dissolved state in solution. Waters with high dissolved solids generally are of lower palatability and may encourage an unfavorable physiological reaction in the transient consumer. This is related to such factors as the geological character of watershed, rainfall and the amount of surface runoffs. It has been reported that farmers use artificial animal feeds to supplement pond, nutrients which has been reported to increase total dissolved solids.

The result Turbidityof this study in line with Bira dam (21.26-27.27) but lower than Tekeze dam (8-11) [15]. The higher difference might be because of highly degraded watershed proximate to the dam resulted higher siltation. According to Santhosh and Singh [16] the secchi disk transparency between 30 and $40 \mathrm{~cm}$ indicates optimum productivity of a pond for good fish culture. Total hardness of this study varied from 0.23 to $0.31 \mathrm{mg} / \mathrm{L}$. This value is very low which could be mean that fishes may be stressed up due to lack of calcium and magnesium needed for bone and scale formation. The recommended ideal value of hardness for fish culture is at least $20 \mathrm{mg} / \mathrm{L}[17]$ and a range of $30-180 \mathrm{mg} / \mathrm{L}$. The calcium hardness of water in Denbi reservoir obtained ranged from 1.06 to $1.8 \mathrm{mg} / \mathrm{L}$. This value is very low when compared with the WHO values $200 \mathrm{mg} / \mathrm{L}$ and 25 $100 \mathrm{mg} / \mathrm{L}$ values for optimum productivity of fish [18].

Nitrate concentrations in this study ranged from 0.044 to $0.1056 \mathrm{mg} / \mathrm{L}$. The result of nitrate obtained was within the acceptable range as recommended by Meck [19]. A nitrate concentration from 0 to $200 \mathrm{mg} / \mathrm{L}$ are acceptable in a fish pond and is generally low toxic for some species whereas especially the marine species are sensitive to its presence. According to Stone and Thomforde ${ }^{14}$ nitrate is relatively nontoxic to fish and not cause any health hazard except at exceedingly high levels (above $90 \mathrm{mg} / \mathrm{L}$ ). Santhosh and Singh ${ }^{16}$ described the favourable range of $0.1 \mathrm{mg} / \mathrm{L}$ to $4.0 \mathrm{mg} / \mathrm{L}$ in fish culture water. In the present investigation, sulphate level values ranged from $0.14 \mathrm{mg} / \mathrm{L}$ to $0.16 \mathrm{mg} / \mathrm{L}$ with a mean value of $0.15 \pm 0.01 \mathrm{mg} / \mathrm{L}$. The result obtained shows that sulphate level of water was lower it might be due to there was no addition of organic manure. Sulphate is known as one of the least toxic anions [20].

\section{CONCLUSIONS}

The physic-chemical properties of Denbi reservoir investigated were in general suitable for fish production and productivity except that of total hardness and calcium hardness that were below the standards, which could be mean that fishes may be exposed to stressed up due to lack of calcium and magnesium needed for bone and scale formation. Therefore, the catchment of the dam should be protected to prevent the reservoir from flood; there should be fertilizer application for better productivity of the reservoir

\section{ACKNOWLEDGMENTS}

We would like to express our appreciation to Mizan-Tepi University for funding this study. Lastly, our heartfelt thankfulness to Mr. Zenawi, Mr. Atirse, Mrs. Kasech and our friends for their support, their encouragement and invaluable experience we shared during the entire period of the study.

\section{REFERENCES}

1. Assefa MJ, 2013. Assessment of fish products demand in some water bodies of Oromia, Ethiopia. Int. J. Agric.Sci.Vol. 3(8) pp.628-632 http://www.internationalscholarsjournals.org/

2. Assefa MJ, 2014. Fish Production, Consumption and Management in Ethiopia. Res. J. Agric. Environ. Manage. Vol. 3(9), pp. 460-466. http://www.apexjournal.org

3. FAO (Food and Agricultural Organization of the United Nation) 2012. The State of World Fisheries and Aquaculture 2012. Rome. 209 pp. http://www.fao.org/docrep/016/i2727e/i2727e00.htm

4. Bronmark $\mathrm{C}$ and Hansson L,2005. The biology of lakes and ponds.Oxford University Press, Oxford 285 https://www.amazon.com/Biology-Lakes-Ponds-Habitats/

5. Bhatnagar A, Jana SN, Garg SK, Patra BC, Singh G and Barman UK, 2013. Water quality management in aquaculture, In: Course Manual of summerschool on development of sustainable aquaculture technology in fresh and saline waters, CCS Haryana Agricultural, Hisar(India),pp203-210. http://www.ipublishing.co.in/ijesarticles/thirteen/articles/volthree/EIJES31197.pdf

6. Ehiagbonare J and Ogundiran Y,2010. Physico-chemical analysis of fish pond waters in Okada and its environs, Nigeria. African J Biotech.; 9(36):5922-5928 http://www.acadamicjournals.org/AJB

7. Sikoki FD and Veen F,2004. Aspects of water quality and the potential for fish production of Shinro Reservour. Nigeria Living System $\quad$ Sustainabledevelopment; 1 . http://www.entomoljournal.com/archives/2017/vol5issue4/PartP/5-4-74-223.pdf

8. Davenport $\mathrm{Y}, 1993$. Responses of the Blennius pholis to fluctuating salinities. Marine Ecology Progress Series, 1 pp 101-107 http://www.isca.in/IJENS/Archive/v7/i2/7.ISCA-IRJEvS-2017-155.php

9. Tesfaye and Wolff, 2014. The state of inland fisheries in Ethiopia: a synopsis with updated estimates of potential yield. https://www.researchgate.net/.../262767900_The_state_of_inland_fisheries_in_Ethiopia

10 Bhatnagar A and Devi P 2013. Water Quality Guidance for the Management of Pond Fish 
Culture.intlJ.Environ. Sci. 3 (6) 1980 - 1993. doi: 10.6088/ijes.2013030600019

11 Agbaire, Patience Odafevejiri, Akporido, Samuel Omorovie and Emoyan Onoriode Onos, 2015. Determination of Some Physicochemical Parameters of Water from Artificial Concrete Fish Ponds In Abraka And Its Environs, DeltaState,NigeriaIjpaes5(3) http://www.ijpaes.com/adimn/php/uploads/841-pdf

12 Abowei, JFN,2010. Salinity, Dissolved Oxygen, $\mathrm{pH}$ and Surface Water Temperature Conditions in Nkoro River, Niger Delta, Nigeria. Advance Journal of Food Science and Technology, 2(1) 36-40. https://maxwellsci.com/print/ajfst/v2-36-40.pdf

13. Boyd C E, 1979. Water quality in Warm Water Fish Ponds. University PressAlabama,USA,59. http://Aurora.auburn.edu/repo/bitstream/handle/11200/1088/0192FISH. Pdf

14. Stone NM and Thomforde HK, 2004. Understanding Your Fish Pond Water Analysis Report. Cooperative Extension Program, University of Arkansas at Pine Bluff Aquaculture/Fisheries, USA. https://fisheries.tamu.edu/files/2013/09/Understanding-Your-Fish-Pond-Water-Analysis-Report.pdf

15 Tessema A, Mohammed A, Birhanu T, Negu T, 2014. Assessment of Physico-chemical Water Quality of Bira Dam, BatiWereda, AmharaRegion, Ethiopia. J Aquac Res Development 5: 267. doi:10.4172/21559546.1000267.

16 Santhosh, B. and Singh, NP. 2007. Guidelines for water quality management for fish culture in Tripura, ICAR Research

http://www.kiran.nic.in/pdf/farmers_corner/pamphlets/Guidelines_for_water_quality_management_for_Fis h_culture_in_tripura.pdf

17. Swann LD, 1997. A Fish Farmer's Guide to Understanding Water Quality, Aquaculture Extension Illinois, Pardue University, Indiana Sea Grant Program Fact Sheet, AS-503. https://www.extension.purdue.edu/extmedia/AS/AS-503.pdf

18 WHO (World Health Organization, 2009. Guideline for Drinking Water Quality, Geneva. https://apps.who.int/iris/bitstream/handle/10665/44584/9789241548151_eng.pdf

19 Meck, Norm. 1996. Pond water chemistry, San Diego, Koi Club, Http:// users.vcnet.com/rrenshaw/h2oquality.html Revised on July 31, 1996. http://www.vskc.net/Member_Input/Water_Quality-Norm_Meck/WaterChemistry.pdf

20 Kiran, B R. 2010. Physicochemical characteristics of fish ponds of Bhadra project at Karnataka. Rasāyan Journal of chemistry 3: (4) 671-676. http://www.rasayanjournal.com 